\title{
Endovascular treatment for acute traumatic transection of the descending aorta: Focus on operative timing and left subclavian artery management
}

\author{
Luca Botta, MD, ${ }^{\mathrm{a}}$ Vincenzo Russo, MD, ${ }^{\mathrm{b}}$ Carlo Savini, MD, ${ }^{\mathrm{a}}$ Katia Buttazzi, MD, ${ }^{\mathrm{b}}$ Davide Pacini, MD, ${ }^{\mathrm{a}}$ Luigi Lovato, MD, \\ Cesare La Palombara, MD, ${ }^{\mathrm{b}}$ Mario Parlapiano, MD, ${ }^{\mathrm{a}}$ Roberto Di Bartolomeo, MD, ${ }^{\mathrm{a}}$ and Rossella Fattori, $\mathrm{MD}^{\mathrm{b}}$
}

Objective: The operative timing and management of acute traumatic aortic rupture are matters of debate. We reviewed our experience with endovascular repair of acute traumatic aortic rupture, focusing on these topics.

\begin{abstract}
Methods: From 1998 to 2007, 31 patients were referred to our institute for acute traumatic rupture of the descending aorta. In 11 patients (group I) an early stent graft procedure was performed, whereas in 16 patients (group II) endovascular repair was delayed. The median time from trauma was 24 hours in group I and 1.5 months in group II. Eight $(25.8 \%$ ) patients had a short proximal neck ( $<5 \mathrm{~mm}$ from the left subclavian artery). Of these, 2 had the left subclavian artery totally covered by the endoprosthesis, and 2 had the left subclavian artery partially covered. Four patients with a posttraumatic pseudoaneurysm involving the left subclavian artery (3 patients) or the left common carotid artery (1 patient) underwent conventional open surgical intervention.
\end{abstract}

Results: Technical success was obtained in all patients. There were neither intraoperative nor perioperative deaths. Cerebellar stroke was detected in 1 patient after the intentional closure of the left subclavian artery. Follow-up (32.7 \pm 27.5 months) was $100 \%$ complete. No late deaths, endoleaks, or complications occurred.

Conclusion: The endovascular approach was a safe and flexible procedure in traumatic aortic rupture and allowed us to fit the operative timing to every patient's clinical and imaging findings. In the presence of an inadequate proximal landing zone, conventional open surgical intervention still remains a favorable option as an alternative to endovascular procedures if a surgical revascularization of the left subclavian artery, carotid artery, or both is necessary.

Traumatic aortic rupture (TAR) of the descending aorta (DA) is a life-threatening condition of high social impact, often involving young persons and leading to immediate death in $75 \%$ to $90 \%$ of cases. ${ }^{1-3}$ Vehicle accidents have accounted for more than $75 \%$ of cases of TAR in most series. Other causes include fall from height, compression by a heavy object, and a direct blow. Aortic injury results from rapid deceleration and the application of shearing forces. $^{4,5}$ TAR has long been considered a surgical emergency, despite the high morbidity and mortality reported in surgical series for emergency aortic repair of patients with polytrauma. ${ }^{6-8}$ Better results were achieved in delaying surgical repair in patients with combined multiple injuries by first addressing the life-threatening injury without fixed priorities. ${ }^{9-11}$ Recently, endovascular stent graft treatment has been proposed as an alternative to open repair in traumatic ruptures with encouraging outcomes. ${ }^{12,13}$ However, the optimal timing and treatment strategy of this low-invasive op-

From the Cardiac Surgery Unit ${ }^{\mathrm{a}}$ and the Cardiovascular Radiology Unit, ${ }^{\mathrm{b}}$ Cardiothoracovascular Department, University Hospital S. Orsola, Bologna, Italy.

Received for publication Feb 12, 2008; revisions received April 23, 2008; accepted for publication July 26, 2008.

Address for reprints: Rossella Fattori, MD, Cardiothoracovascular Department (Pad 21), University Hospital S. Orsola-Malpighi, Via Massarenti 9, 40138 Bologna,

Italy (E-mail: rossella.fattori@unibo.it).

J Thorac Cardiovasc Surg 2008; 136:1558-63

$0022-5223 / \$ 34.00$

Copyright (c) 2008 by The American Association for Thoracic Surgery doi:10.1016/j.jtcvs.2008.07.040 tion is essential to achieve satisfactory and durable results. We reviewed our experience of 9 years with endovascular management to define potential guidelines.

\section{MATERIALS AND METHODS Patients}

This retrospective study has been approved by the local ethics committee, and written informed consent has been obtained from all involved patients. From July 1998 to September 2007, 31 patients (27 male and 4 female patients) were referred to our department with a diagnosis of acute posttraumatic rupture of the DA. All patients with chronic posttraumatic pseudoaneurysm of the DA were excluded from this study. The mean age was $36.9 \pm 10.3$ years (range, 19-54 years), and the mean American Society of Anesthesiologists class was $3.2 \pm 1.2$. Routine examination of heart, lung, liver, and kidney function and contrast-enhanced computed tomographic (CT) scanning, magnetic resonance imaging (MRI), and/or angiographic analysis were conducted in all hemodynamically stable patients. Hemodynamically compromised patients underwent CT analysis, transesophageal echocardiographic (TEE) analysis, or both just before emergency endovascular repair. Selective imaging of the circle of Willis was not routinely performed in this series before the procedure. Twenty-seven patients underwent endovascular repair, and 4 underwent conventional open surgical intervention.

\section{Endovascular Repair: Selection Criteria and Timing}

Early endovascular procedures were performed in 11 patients (group I) with a median time from trauma of 24 hours (range, 5-120 hours). In particular, 5 of 11 patients in group I presenting with an unstable clinical picture and precarious hemodynamic stability were treated under emergency conditions ( $<24$ hours). A delayed endovascular approach was carried out in the other 16 patients (group II), with a median time from trauma of 1.5 months 

Abbreviations and Acronyms
$\mathrm{CT}=$ computed tomography
$\mathrm{DA}=$ descending aorta
LSA $=$ left subclavian artery
MRI = magnetic resonance imaging
$\mathrm{TAR}=$ traumatic aortic rupture
$\mathrm{TEE}=$ transesophageal echocardiography

(range, $0.8-18$ months). Isolated TAR was present in $6(22.2 \%)$ patients, and associated lesions were detected in $21(77.8 \%)$ patients. Anatomic conditions allowing endovascular treatment were considered: no aortic wall alteration (thrombus, severe atherosclerosis, and intramural hemorrhage), as well as a diameter of $42 \mathrm{~mm}$ or less and $20 \mathrm{~mm}$ or greater at the proximal and distal necks, a diameter of the femoral or iliac arteries of $8 \mathrm{~mm}$ or greater, and no extension of the aortic lesion to the aortic arch. Conventional surgical intervention was performed when an unsuitable anatomy for endovascular devices was detected by means of imaging studies (aortic arch involvement in 4 patients and femoral/iliac artery $<6 \mathrm{~mm}$ in 1 patient). An early endovascular procedure was performed under emergency conditions in patients with hemodynamic instability and imaging findings of aortic impending rupture. Signs of impending rupture were considered: discontinuity of aortic contour, contrast media extravasation, rapid growth rate of pseudoaneurysm, periaortic hematoma, and/or hemorrhagic pleural effusion. ${ }^{14}$ In the absence of the above-mentioned conditions, the acute aortic injury was medically stabilized, strictly followed up, and treated after the resolution of the major associated lesions without fixed priorities.

\section{Left Subclavian Artery Management}

The mean aortic diameter at the level of transection was $33.3 \pm 6.6 \mathrm{~mm}$, whereas the mean proximal and distal neck diameters were $22.6 \pm 2.6 \mathrm{~mm}$ and $21.7 \pm 2 \mathrm{~mm}$, respectively. Preoperative data of each group are shown in Table $1 .{ }^{15}$ Eight patients had an inadequate proximal landing zone $(<5$ $\mathrm{mm}$ from the origin of the left subclavian artery [LSA]): 4 of them presented with a postraumatic pseudoaneurysm extended to/over the LSA (3 patients) or to the left common carotid artery (1 patient) and were treated with conventional open surgical intervention at a median time of 25 days from trauma. In the other 4 patients, an endovascular repair was attempted. In 2 of them the stent graft totally covered the LSA, whereas in the 2 other patients, the LSA was partially covered but left an adequate antegrade flow, according to postoperative TEE information and CT scan imaging (Figure 1).

\section{Stent Graft Procedure and Conventional Surgical Intervention}

All endovascular procedures were performed in the operating room, as previously described. ${ }^{16}$ During general anesthesia, patients received mechanical ventilation. Blood pressure was monitored by means of right radial artery cannulation. Ceftriaxone ( $2 \mathrm{~g}$ administered intravenously) was administered before the procedure. Cerebrospinal fluid drainage was never used in this series of patients. The common femoral artery was used for access after surgical exposure. After exposition of the artery, a $6 \mathrm{~F}$ sheath was inserted, and $2500 \mathrm{IU}$ of heparin was administered. In patients with active bleeding into the pleural space, mediastinal space, or both, no systemic heparin was administered. Angiographic analysis was performed to identify the lesion, its landing zones, and its relation to the side branches. Twenty-eight thoracic stent grafts (23 Talent and 5 Valliant; Medtronic, Santa Rosa, Calif) were loaded on an extrastiff guidewire and delivered under fluoroscopic and TEE control with induced hypotension (systolic pressure, $<100 \mathrm{~mm} \mathrm{Hg}$ ) to prevent inadvertent downstream displacement of the stent graft during de-
TABLE 1. Clinical profile

\begin{tabular}{|c|c|c|c|}
\hline Variables & $\begin{array}{l}\text { Group I } \\
(\mathbf{n}=\mathbf{1 1})\end{array}$ & $\begin{array}{c}\text { Group II } \\
(\mathbf{n}=16)\end{array}$ & $\begin{array}{c}P \\
\text { value }\end{array}$ \\
\hline Age $(y) \pm S D$ (range) & $38.5 \pm 12.3(21-55)$ & $35.8 \pm 10.2(19-54)$ & NS \\
\hline Sex (male/female) & $9 / 2$ & $15 / 1$ & NS \\
\hline ASA class \pm SD & $4.4 \pm 0.5$ & $2.4 \pm 0.7$ & \\
\hline Hemothorax & 6 & 4 & NS \\
\hline Isolated TAR & 1 & 5 & NS \\
\hline \multicolumn{4}{|l|}{ Associated Lesions } \\
\hline Orthopedic & 9 & 8 & NS \\
\hline Thoracic & 8 & 7 & NS \\
\hline Neurologic & 2 & 3 & NS \\
\hline Abdominal & 0 & 6 & .05 \\
\hline $\begin{array}{l}\text { Revised trauma } \\
\text { score }^{15}\end{array}$ & $9.3 \pm 1.7$ & $9.9 \pm 1.7$ & NS \\
\hline \multicolumn{4}{|l|}{ Diagnostic tools } \\
\hline $\mathrm{CT}$ & 11 & 8 & .008 \\
\hline Angiography & 1 & 11 & .004 \\
\hline MRI & 1 & 10 & .007 \\
\hline Inadequate neck & 2 & 2 & NS \\
\hline $\begin{array}{l}\text { Aortic diameter } \\
\text { at TAR level } \\
\quad(\mathrm{mm}) \pm \mathrm{SD}\end{array}$ & $33 \pm 7$ & $33.3 \pm 6.8$ & NS \\
\hline $\begin{array}{l}\text { Proximal landing } \\
\text { zone diameter } \\
(\mathrm{mm}) \pm \mathrm{SD}\end{array}$ & $22 \pm 3$ & $23.1 \pm 2.5$ & NS \\
\hline $\begin{array}{l}\text { Distal landing } \\
\text { zone diameter } \\
\quad(\mathrm{mm}) \pm \mathrm{SD}\end{array}$ & $21.8 \pm 2.6$ & $21.8 \pm 2$ & NS \\
\hline $\begin{array}{l}\text { Time from } \\
\text { trauma* (range) }\end{array}$ & $24 \mathrm{~h}(5-120)$ & $1.5 \mathrm{mo}(0.8-18)$ & \\
\hline
\end{tabular}

Values are presented as the mean \pm standard deviation $(S D)$ or number of patients experiencing the event followed by the corresponding percentage in parentheses, unless otherwise noted. NS, Not significant; ASA, American Society of Anesthesiologists; $T A R$, traumatic aortic rupture; $C T$, computed tomography; MRI, magnetic resonance imaging. *Median value.

livery. Stent graft distribution and diameters are specified in Table 2. The proximal end of the endografts was always an uncovered stent (free-flow end). On the basis of CT/MRI measurement, an oversizing of $10 \%$ to $20 \%$ was applied in the choice of stent graft diameter. Compliant aortic occlusion balloons were selectively used to improve wall adhesion of the stent grafts. Postprocedural angiographic analysis and TEE control were performed to reveal the final result.

Conventional surgical intervention was performed in 4 cases. Surgical access was obtained through a left thoracotomy in 3 patients and a median sternotomy in 1 patient. The surgical techniques consisted of graft replacement of the ruptured segment of the aorta in all cases, with reimplantation of the involved supra-aortic vessels. Spinal cord protection and distal organ perfusion were achieved by the use of left heart bypass when the posttraumatic pseudoaneurysm was extended only to the LSA. In 1 patient the aortic repair had to be carried out during circulatory arrest with deep hypothermia because of the proximal extension of the aortic tear into the transverse arch.

\section{RESULTS}

No operative mortality occurred in patients submitted to open surgical intervention. These patients were all transferred to the intensive care unit. Median intubation time, intensive care unit stay, and in-hospital stay were 14 hours, 26 

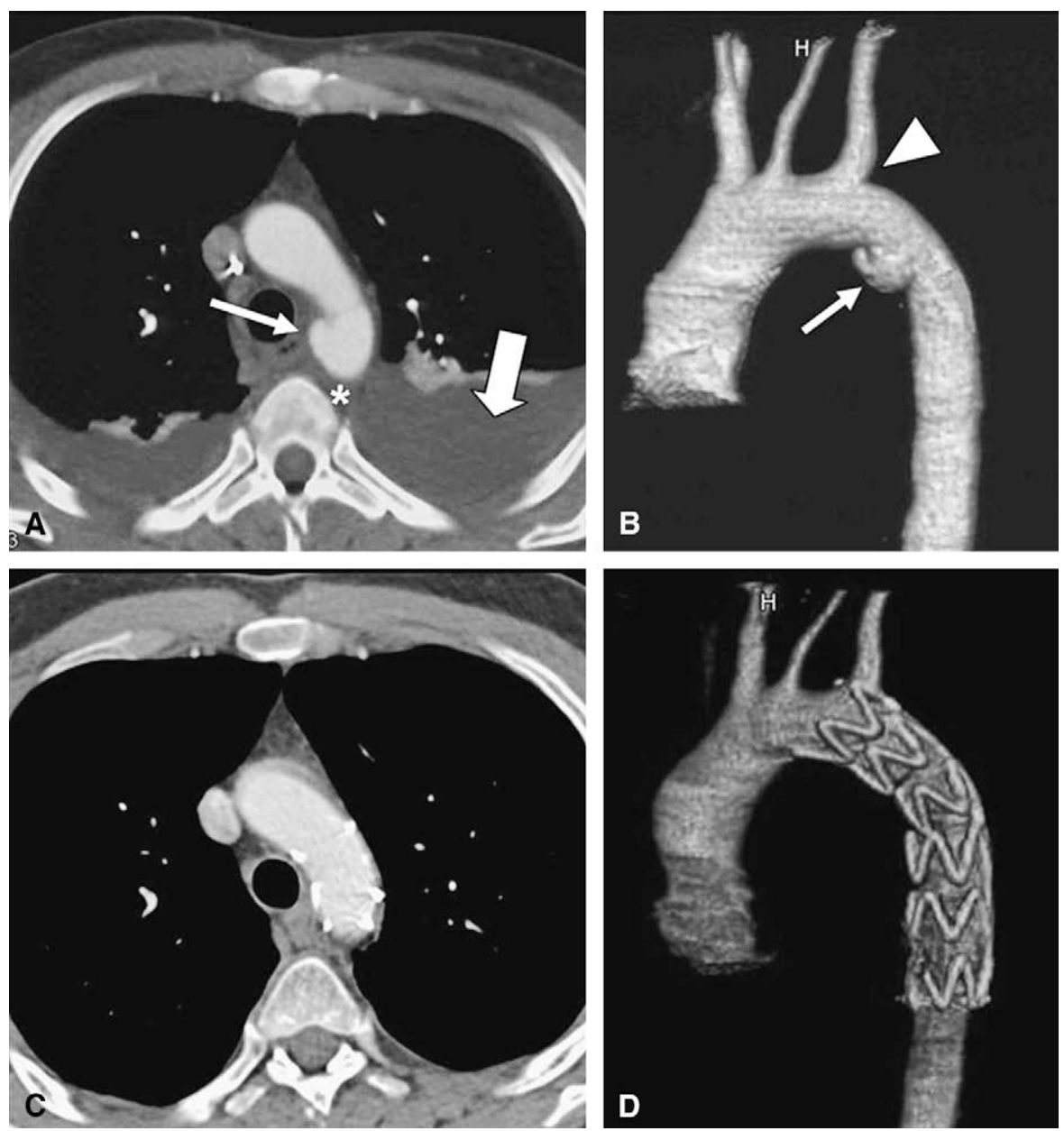

FIGURE 1. Multidetector computed tomographic axial (A and C) and 3-dimensional (B and D) images of a posttraumatic pseudoaneurysm of the aortic isthmus before ( $\mathrm{A}$ and $\mathrm{B}$ ) and after (C and D) endovascular treatment. The lesion (arrow), the periaortic hematoma (*), and the pleural effusion (large arrow) are shown, as well as the short proximal neck for stent graft release (arrowhead). After device delivery, the lesion is excluded with left subclavian artery flow preservation.

hours, and 8 days, respectively. No patient experienced stroke, paraplegia, or other major complications.

Technical success was obtained in all patients submitted to stent graft repair $(100 \%)$. The right common femoral artery was used as surgical access in all endovascular cases. No mortality or failure of the endovascular procedure or endoleak was observed. One 22-year-old patient of group I had cerebellar ischemia after intentional closure of the LSA. MRI documented a large cerebellar infarction in the territory of the left vertebral artery. No anomalies of the circle of Willis were detected on magnetic resonance angiographic analysis performed after the onset of this dreadful complication.

Clinical examination, CT scanning, or MRI controls were performed at discharge and 1,3/6, and 12 months after treatment and every 12 months thereafter in patients treated with endovascular repair. Follow-up was $100 \%$ complete. The mean follow-up time was $32.7 \pm 27.5$ months. A reduction of the involved aortic segment was detected in all patients $(27.5 \pm 6.5 \mathrm{~mm}$ for follow-up mean diameter vs $33.3 \pm$
$6.6 \mathrm{~mm}$ for preoperative mean diameter), with a complete shrinkage in the majority of cases. No late complications or endoleak occurred. Outcome and follow-up details for each group are shown in Tables 2 and 3, respectively.

\section{DISCUSSION}

Traumatic rupture of the thoracic aorta is second only to head injury as the most common cause of death after blunt trauma. The natural history of TAR is dominated by fear of subsequent rupture. The timing of this event is unpredictable and ranges from a few hours to months. Operative timing and management of this complex condition are nowadays matters of debate. ${ }^{1,2}$ A mandatory surgical treatment has been emphasized for patients arriving alive at the hospital. Despite advances in surgical and reanimation techniques, surgical intervention for acute aortic rupture is still associated with significant morbidity and a high mortality rate up to $50 \%{ }^{6,7}$ Rousseau and colleagues ${ }^{17}$ reported mortality and paraplegia rates of $21 \%$ and $7 \%$, respectively, in 
TABLE 2. Procedural data

\begin{tabular}{|c|c|c|c|}
\hline Variables & $\begin{array}{l}\text { Group I } \\
(\mathbf{n}=\mathbf{1 1})\end{array}$ & $\begin{array}{l}\text { Group II } \\
(\mathbf{n}=16)\end{array}$ & $\begin{array}{c}P \\
\text { value }\end{array}$ \\
\hline Time from trauma* (range) & 24 h $(5-120)$ & $1.5 \mathrm{mo}(0.8-18)$ & \\
\hline Technical success & 11 & 16 & NS \\
\hline \multicolumn{4}{|l|}{ Surgical access } \\
\hline Common femoral artery & 11 & 13 & NS \\
\hline External iliac artery & 0 & 3 & NS \\
\hline Stent grafts per patient & 1 & $1-2$ & NS \\
\hline $\begin{array}{l}>1 \text { Stent graft used } \\
\quad(\text { maximum })\end{array}$ & 0 & $1(2)$ & NS \\
\hline \multicolumn{4}{|l|}{ Type of stent graft } \\
\hline Talent & 9 & 14 & \\
\hline Valiant & 2 & 3 & \\
\hline \multicolumn{4}{|l|}{ Stent graft diameters } \\
\hline $22 / 22 \mathrm{~mm}$ & 1 & 1 & \\
\hline $24 / 24 \mathrm{~mm}$ & 2 & 2 & \\
\hline $26 / 26 \mathrm{~mm}$ & 4 & 6 & \\
\hline $28 / 28 \mathrm{~mm}$ & 1 & 2 & \\
\hline $30 / 30 \mathrm{~mm}$ & 2 & 3 & \\
\hline $32 / 32 \mathrm{~mm}$ & 1 & 3 & \\
\hline \multicolumn{4}{|l|}{ Left subclavian artery closure } \\
\hline Complete & 2 & 0 & NS \\
\hline Partial & 0 & 2 & NS \\
\hline Stent graft length $(\mathrm{mm}) \pm \mathrm{SD}$ & $130 \pm 7.9$ & $123.5 \pm 17.5$ & NS \\
\hline $\begin{array}{l}\text { Fluoroscopic time } \\
(\mathrm{mm}) \pm \mathrm{SD}\end{array}$ & $13 \pm 6$ & $10.5 \pm 3.5$ & NS \\
\hline Contrast media $(\mathrm{mL}) \pm \mathrm{SD}$ & $99.5 \pm 33.5$ & $112.8 \pm 34.6$ & NS \\
\hline Intraoperative use of TEE & 11 & 16 & NS \\
\hline Surgical conversion & 0 & 0 & \\
\hline Endoleak & 0 & 0 & \\
\hline Intraoperative mortality & 0 & 0 & \\
\hline
\end{tabular}

28 patients treated with immediate surgical repair. Our own group $^{10}$ reported $19 \%$ mortality and $14.3 \%$ paraplegia after emergency surgical intervention. Since the 1990s, delayed surgical repair has been considered in patients with TAR who present with hemodynamic stability and do not have imaging findings of impending rupture. ${ }^{18}$ The rationale behind this trend is that in the majority of those patients who make it to the hospital alive, the adventitia and surrounding mediastinal structures remain partially intact, thus preserving the integrity of the disrupted aorta. In stable lesions of the aorta, initial conservative treatment is safe and allows management of the major life-threatening associated lesions. ${ }^{9-11,17-21}$ In the last years, endovascular stent graft treatment has been proposed as an alternative to open repair in traumatic ruptures, with encouraging outcomes. Single institutional experiences have confirmed the safety and feasibility of endovascular treatment of TAR. ${ }^{12,13,16-18,22-24}$ The theoretic advantages of endovascular treatment of acute rupture of the thoracic aorta are multiple. A simple arteriotomy is performed without thoracotomy or aortic clamping.
TABLE 3. Outcome and follow-up

\begin{tabular}{|c|c|c|c|}
\hline Variables & $\begin{array}{l}\text { Group I } \\
(\mathbf{n}=\mathbf{1 1})\end{array}$ & $\begin{array}{l}\text { Group II } \\
(\mathrm{n}=16)\end{array}$ & $\begin{array}{c}P \\
\text { value }\end{array}$ \\
\hline Surgical conversion & 0 & 0 & \\
\hline Endoleak & 0 & 0 & \\
\hline Intraoperative mortality & 0 & 0 & \\
\hline Intubation time* (range) & $10 \mathrm{~h}(4-240)$ & $6 \mathrm{~h}(2-12)$ & .048 \\
\hline In-hospital stay* (range) & $6 \mathrm{~d}(2-23)$ & $5.5 \mathrm{~d}(4-8)$ & NS \\
\hline In-hospital mortality & 0 & 0 & \\
\hline \multicolumn{4}{|l|}{ In-hospital morbidity } \\
\hline $\begin{array}{l}\text { Second endovascular } \\
\text { procedure }\end{array}$ & 0 & 0 & \\
\hline Paraplegia & 0 & 0 & \\
\hline Stroke & 1 & 0 & NS \\
\hline Renal complications & 0 & 0 & \\
\hline $\begin{array}{l}\text { Respiratory } \\
\text { complications }\end{array}$ & 1 & 0 & NS \\
\hline \multicolumn{4}{|l|}{ Follow-up } \\
\hline No. of patients & 11 & 16 & \\
\hline Mean time \pm SD (mo) & $20.5 \pm 16.8$ & $41.4 \pm 28.9$ & \\
\hline Median time (range) & $18(6-60)$ & $42(6-84)$ & \\
\hline Stent-related deaths & 0 & 0 & \\
\hline $\begin{array}{l}\text { Stent-related } \\
\text { complications }\end{array}$ & 0 & 0 & \\
\hline Overall deaths & 0 & 0 & \\
\hline Other complications & 0 & 0 & \\
\hline $\begin{array}{l}\text { Diameter at TAR Level } \\
\quad(\mathrm{mm}) \pm \mathrm{SD}\end{array}$ & $26.8 \pm 5.9$ & $28.4 \pm 7$ & NS \\
\hline $\begin{array}{l}\text { Proximal neck } \\
\quad \text { diameter }(\mathrm{mm}) \pm \mathrm{SD}\end{array}$ & $23.7 \pm 3.1$ & $23.6 \pm 2.6$ & NS \\
\hline $\begin{array}{l}\text { Distal neck } \\
\quad \text { diameter }(\mathrm{mm}) \pm \mathrm{SD}\end{array}$ & $22.2 \pm 2.2$ & $22.3 \pm 2.3$ & NS \\
\hline
\end{tabular}

Values are presented as the mean \pm standard deviation $(S D)$ or number of patients ex periencing the event followed by the corresponding percentage in parentheses, unless otherwise noted. $N S$, Not significant; TAR, traumatic aortic rupture. ${ }^{*}$ Median value.

The risk of medullar ischemia is less than that of conventional surgical intervention because of the absence of aortic clamping and the location of the aortic injury. Furthermore, this approach does not aggravate head or abdominal injuries and pulmonary contusions because intraoperative lung ventilation is limited and systemic heparinization is not necessary.

Currently, we consider all patients to be candidates for endograft approaches if the anatomy is suitable. Patients arriving alive with TAR are admitted to the intensive care unit and immediately undergo intensive resuscitation, with limited fluid administration and administration of $\beta$-blockers (metoprolol) and vasodilators (sodium nitroprusside, calcium-channel blockers, and nitrates), often in combination, to maintain a systolic blood pressure of about $100 \mathrm{~mm} \mathrm{Hg}$. Patients admitted with or having in-hospital clinical (hypovolemic shock, hemodynamic instability, uncontrolled blood pressure, oligoanuria, or signs of other vital organ compromise) or imaging findings of impending rupture (contrast media extravasation, periaortic hematoma, 
hemorrhagic pleural effusion, discontinuity of aortic contour, and rapid growth rate of pseudoaneurysm) are candidates for immediate repair. In stable patients we believe that the endovascular treatment could be delayed after intensive medical therapy, giving priority to the other significant and life-threatening associated injuries when present. According to previous experience with delayed open surgical intervention, the risk of aortic rupture for patients surviving the traumatic impact is very low after 6 to 8 hours from trauma. ${ }^{9,18}$ However, with growing awareness of safety and limited invasiveness of endovascular techniques, it is also possible to treat these patients early after initial hemodynamic stabilization.

Stent graft procedures require suitable proximal and distal attachment zones. There is no general consensus regarding how best to handle patients with proximal descending thoracic aortic injuries. A number of strategies have been described for managing the LSA during aortic stenting in patients with a short juxtasubclavian neck, including intentional closure, coil embolization, preoperative or postoperative subclavian-carotid bypass, or transposition. In our series the intentional closure of the LSA caused a cerebellar stroke in a 22-year-old patient of group I, despite the absence of any alteration of the circle of Willis. This dramatic event and a careful review of the literature ${ }^{25-28}$ induced us to avoid closure of the LSA without previous revascularization. An effective and unpredictable risk of cerebral ischemic complications caused by abrupt closure of the vertebral artery should be considered in these patients, as attested by several reports. Weigang and associates ${ }^{26}$ and Riesenman and coworkers,${ }^{27}$ respectively, reported the development of central adverse neurologic events in $2(10 \%)$ of 20 and $3(10.7 \%)$ of 28 patients after overstenting of the LSA without previous revascularization. In a recent article Brett Reece and colleagues of the University of Virginia ${ }^{28}$ suggested that selective revascularization after endovascular repair with exclusion of the origin of the LSA might be required more frequently than previously reported. Flow compensation throughout the circle of Willis is a dynamic process that can be influenced by the diameter of the posterior communicating arteries and vasomotor regulation. ${ }^{25-30}$ Focusing our attention on acute traumatic ruptures of the DA, we should also consider that cerebral edema, often associated even with mild head trauma, and general anesthesia might potentially influence vasomotor effects in the cerebral circulation.

In young patients the association of endovascular procedures and carotid-subclavian bypass could be criticized because both operations have no long-term follow-up regarding integrity and durability. Several articles addressed the outcomes of carotid-subclavian bypass, reporting a graft patency of between $66 \%$ and $89 \%$ at a maximum follow-up of 15 years. ${ }^{31-33}$ Unfortunately, these data concern atherosclerotic lesions of supra-aortic vessels and are not applicable to this cohort of patients. Therefore if traumatic injuries of the aorta involve young patients with an inadequate landing zone for stent graft deployment, we prefer to proceed with conventional open surgical treatment as an alternative option to endovascular repair associated with surgical revascularization of the LSA. This decision is strengthened by the excellent results in terms of morbidity and mortality of our group in "elective" open operations after intensive medical stabilization. ${ }^{18}$

This study suggests that endovascular treatment is a safe and flexible procedure in acute TAR and can be used with excellent results, adapting itself to the features of every patient. We did not observe any early or late treatment failure or graft material alteration after 11 years of endovascular experience with close imaging follow-up. The greater feasibility of endovascular repair in the acute phase of the injury is a major advantage over traditional open surgical treatment. On the other hand, when clinical conditions enable it, stent graft procedures can be safely delayed, allowing the management of the major associated lesions.

\section{CONCLUSION}

Unlike conventional surgical intervention, endovascular treatment of acute posttraumatic DA rupture shows excellent results both as an immediate and delayed approach. The correct timing of aortic repair in a patient with polytrauma should be considered and balanced along with other severe injuries, without a fixed priority. Stent graft repair is a feasible, safe, and flexible procedure in TAR and allowed us to adapt the operative timing to every patient's clinical and imaging findings. In the presence of an inadequate proximal landing zone, conventional open surgical intervention still remains a favorable option as an alternative to endovascular repair associated with surgical revascularization of the LSA. More cases and longer follow-up are necessary to determine the ultimate treatment strategy.

\section{References}

1. Nzewi O, Slight RD, Zamvar V. Management of blunt thoracic aortic injury. Eur J Vasc Endovasc Surg. 2007;31:18-27.

2. Parmley LF, Mattingly TW, Marian WC. Non-penetrating traumatic injury of the aorta. Circulation. 1958; 17:1086-100.

3. Greendyke RM. Traumatic rupture of aorta. Special reference to automobile accidents. JAMA. 1996;195:119-22.

4. Feczko JD, Lynch L, Pless JE, Clark MA, McClain J, Hawley DA. An autopsy case review of 124 non-penetrating (blunt) injuries of the aorta. J Trauma. 1992;33:846-9.

5. Sevitt S. The mechanism of traumatic rupture of the thoracic aorta. Br J Surg. 1977;64:166-73.

6. Von Oppell UO, Dunne TT, DeGroot MK, et al. Traumatic aortic rupture: 20-year meta-analysis of mortality and risk of paraplegia. Ann Thorac Surg. 1994;58: 585-93.

7. Fabian TC, Richardson JD, Croce MA, et al. Prospective study of blunt injury: multicenter trial of the American Association for Surgery of Trauma. J Trauma. 1997;42:374-80.

8. Kouchoukos NT, Dougenis D. Surgery of the thoracic aorta. N Engl J Med. 1997; 336:1876-88.

9. Pate JW, Fabian TC, Walker W. Traumatic rupture of the aortic isthmus: an emergency? World J Surg. 1995;19:119-26. 
10. Galli R, Pacini D, Di Bartlomeo R, et al. Surgical indications and timing of traumatic ruptures of the thoracic aorta. Ann Thorac Surg. 1998;65:461-4.

11. Maggisano R, Nathens A, Alexandrova N. Traumatic rupture of the thoracic aorta: should one always operate immediately? Ann Vasc Surg. 1995;9:44-52.

12. Fattori R, Napoli G, Lovato L, et al. Indications for, timing of, and results of catheter-based treatment of traumatic injury to the aorta. Am J Roentgenol. 2002;179: 603-9.

13. Thompson CS, Rodriguez JA, Ramaial VG, et al. Acute traumatic rupture of the thoracic aorta treated with endovascular stent graft. J Trauma. 2002;52:1173-7.

14. Gavant ML. Helical CT grading of traumatic aortic injuries. Impact on clinical guidelines for medical and surgical management. Radiol Clin North Am. 1999; 37:553-74.

15. Champion HR, Sacco WJ, Copes WS, Gann DS, Gennarelli TA, Flanagan ME. A revision of the trauma score. J Trauma. 1989;29:623-9.

16. Fattori R, Buttazzi K, Russo V, et al. Evolving concepts in the treatment of traumatic aortic injury. A review article. J Cardiovasc Surg (Torino). 2007;48:625-31.

17. Rousseau H, Dambrin C, Marcheix B, et al. Acute traumatic aortic rupture: a comparison of surgical and stent-graft repair. J Thorac Cardiovasc Surg. 2005;129:1050-5.

18. Pacini D, Angeli E, Fattori R, et al. Traumatic rupture of the thoracic aorta: ten years of delayed management. J Thorac Cardiovasc Surg. 2005;129:880-4.

19. Akins CW, Buckley MJ, Dagget W. Acute traumatic disruption of the thoracic aorta: a ten year experience. Ann Thorac Surg. 1981;31:305-9.

20. Kipfer B, Leupi F, Schuepbach P, et al. Traumatic rupture of the thoracic aorta: immediate or delayed surgical repair? Eur J Cardiothorac Surg. 1994;8:30-3.

21. Prêtre R, Chilcott M. Blunt trauma to the heart and great vessels. $N$ Engl J Med. 1997;336:626-32.

22. Rousseau H, Soula P, Perreault P, et al. Delayed treatment of traumatic rupture of the thoracic aorta with endoluminal covered stent. Circulation. 1999;99:498-504.
23. Doss M, Martens S, Hemmer W. Emergency endovascular interventions for ruptured thoracic and abdominal aortic aneurysms. Am Heart J. 2002;144: 544-8.

24. Fattori R, Napoli G, Lovato L, et al. Descending thoracic aortic diseases: stentgraft repair. Radiology. 2003;229:176-83.

25. Steinberg GK, Drake CG, Peerless SJ. Deliberate basilar or vertebral artery occlusion in the treatment of intracranial aneurysms. Immediate results and long-term outcome in 201 patients. J Neurosurg. 1993;79:161-73.

26. Weigang E, Luehe M, Harloff A, et al. Incidence of neurological complications following overstenting of the left subclavian artery. Eur J Cardiothorac Surg. 2007;31:628-36.

27. Riesenman PJ, Farber MA, Mendes RR, et al. Coverage of the left subclavian artery during thoracic endovascular aortic repair. J Vasc Surg. 2007;45:90-4.

28. Brett Reece T, Gazoni LM, Cherry KJ, et al. Reevaluating the need for left subclavian artery revascularization with thoracic endovascular aortic repair. Ann Thorac Surg. 2007;84:1201-5.

29. Schomer DF, Marks MP, Steimberg GK, et al. The anatomy of the posterior communicating artery as a risk factor for ischemic cerebral infarction. $N$ Engl J Med. 1994;330:1565-70.

30. Pellegrino DA. Regulation of the cerebral circulation. J Appl Physiol. 2006; 100: $3-4$

31. Cinà CS, Safar HA, Laganà A, Arena G, Clase CM. Subclavian carotid transposition and bypass grafting: consecutive cohort study and systematic review. J Vasc Surg. 2002;35:422-9.

32. Uurto IT, Lautamatti V, Zeitlin R, Salenius JP. Long-term outcome of surgical revascularization of supraaortic vessels. World J Surg. 2002;26:1503-6.

33. Deriu GP, Milite D, Verlato F, et al. Surgical treatment of atherosclerotic lesions of subclavian artery: carotid-subclavian bypass versus subclavian-carotid transposition. J Cardiovasc Surg (Torino). 1998;39:729-34. 